Figure. Test characteristics of the presence of difficulties with dressing, with IA at physical examination as outcome

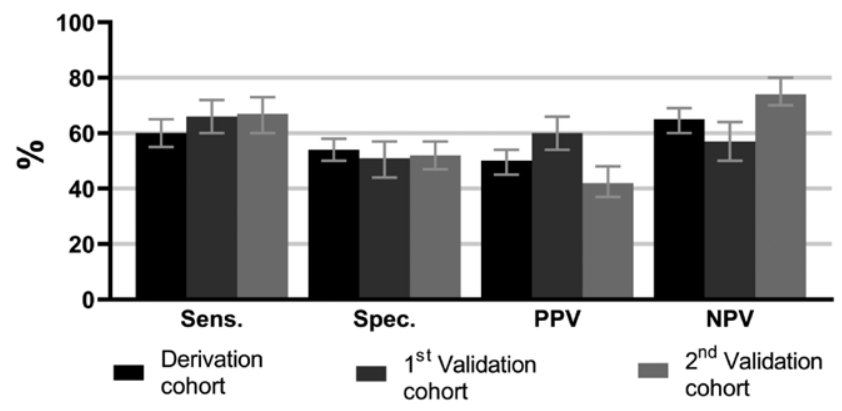

Error bars indicate the $95 \%$ confidence interval.

Sens.: sensitivity; Spec.: specificity; PPV: positive predictive value; NPV: negative predictive value.

Conclusion: A yes/no answer on a simple question ("Are you able to dress yourself, including shoelaces and buttons?") was helpful in discriminating patients with and without IA. Findings were validated in independent 1.5-line settings and need to be validated further in primary care. This is a step forward to arrive at practical tools that are helpful for GPs in identifying early IA.

References:

[1] van Nies JA et al. Improved early identification of arthritis: evaluating the efficacy of Early Arthritis Recognition Clinics. Ann Rheum Dis. 2013;72(8):1295-301.

[2] ten Brinck RM et al. Development and validation of a clinical rule for recognition of early inflammatory arthritis. BMJ Open. 2019 Feb 22;8(11):e023552.

Disclosure of Interests: Bastiaan van Dijk: None declared, Hanna W. van Steenbergen: None declared, Ellis Niemantsverdriet: None declared, Elisabeth Brouwer Consultant of: Roche (consultancy fee 2017 and 2018 paid to the UMCG), Speakers bureau: Roche (2017 and 2018 paid to the UMCG), Annette van der Helm - van Mil: None declared

DOI: 10.1136/annrheumdis-2020-eular.426

\section{FRI0596 \\ NOVEL AUTOANTIBODY BIOMARKERS FOR THE PREDICTION OF THERAPY RESPONSE IN RHEUMATOID ARTHRITIS}

P. Vandormael ${ }^{1}$, A. Pues ${ }^{1}$, E. Sleurs ${ }^{1}$, P. Verschueren ${ }^{2}$, V. Somers ${ }^{1} .{ }^{1}$ Hasselt University, Biomedical Research Institute, Diepenbeek, Belgium; ${ }^{2} \mathrm{KU}$ Leuven, Skeletal Biology and Engineering Research Center, Department of Development and Regeneration, Leuven, Belgium

Background: Rheumatoid arthritis (RA) is an autoimmune disorder that is characterized by chronic inflammation of the joint synovium and presence of autoantibodies in most patients. For RA, many treatments are currently available but each treatment will only induce disease remission in a subset of patients. Moreover, finding out which patients respond well to first-line therapy with classical synthetic disease modifying anti-rheumatic drugs (csDMARDs), still largely depends on trial and error.

Objectives: In this study, we aim to find novel RA autoantibody biomarkers that predict therapy response to csDMARDs before the initiation of treatment.

Methods: In the CareRA trial, a Flemish multicenter study of different treatment regimes, serum samples were collected from RA patients that did or did not show disease remission $(\mathrm{DAS} 28(\mathrm{CRP})<2.6)$ in response to csDMARDs, combined with a step down glucocorticoid treatment. In our study, baseline samples, collected before the start of treatment, were used to determine predictive antibody reactivity. A cDNA phage display library, representing the antigens from RA synovial tissue, was constructed and screened for antibody reactivity in baseline serum samples of RA patients that failed to reach remission at week 16. Using enzyme-linked immunosorbent assays (ELISA), antibody reactivity against the identified antigens was initially determined in pooled baseline serum samples of RA patients that did $(n=50)$ or did not $(n=40)$ reach disease remission at week 16. Antigenic targets that showed increased antibody reactivity in pools from patients that did not reach disease remission, were further validated in individual serum samples of 69 RA patients that did not reach DAS28(CRP) remission at week 16, and 122 RA patients that did.

Results: Screening and validation of antibody reactivity resulted in 41 novel antigens. The retrieved antigenic sequences correspond to (parts of) known proteins and to randomly formed peptides. A panel of 3 of these peptide antigens could be composed, whose baseline antibody reactivity correlated with lack of therapy response at week 16. Presence of antibodies against at least one of these 3 antigens was significantly higher in individual samples of RA patients that did not reach DAS28(CRP) remission (43 vs. $29 \%, p=0.041$ ), or that failed to reach ACR 70 (42 vs. $26 \%, p=0.029$ ) response criteria at week 16 , compared to RA patients that did reach these respective criteria. In addition, RA patients which were positive for this antibody panel at baseline, also showed less DAS(CRP) remission at week 4 and week 8 .

Conclusion: We have identified a set of 3 antibody biomarkers that can predict failure of early disease remission after first-line RA therapy, which might contribute to personalized medicine decisions.

Disclosure of Interests: Patrick Vandormael: None declared, Astrid Pues: None declared, Ellen Sleurs: None declared, Patrick Verschueren Grant/research support from: Pfizer unrestricted chair of early RA research, Speakers bureau: various companies, Veerle Somers Grant/research support from: Research grant from Pfizer and BMS

DOI: 10.1136/annrheumdis-2020-eular.4184

\begin{tabular}{|l|l|}
\hline FRI0597 & IMMUNOGLOBULIN A FOR CD74 AS AN \\
& ALTERNATIVE LABORATORY MARKER FOR \\
& DETERMINING THE ACTIVITY OF AXIAL \\
& SPONDYLOARTHRITIS
\end{tabular}

E. Vasilenko ${ }^{1,2}$, V. Mazurov ${ }^{1}$, S. Lapin ${ }^{3}$, I. Kholopova ${ }^{3}$, A. Dadalova ${ }^{1}$, I. Gaydukova ${ }^{1,2} .{ }^{1}$ North-Western State Medical University named after I.I. Mechnikov, Department of Therapy, Rheumatology, Examination of Temporary Disability and Quality of Medical Care named after E.E.Eichwald, St. Petersburg, Russian Federation; ${ }^{2}$ St. Petersburg Clinical Rheumatology Hospital No.25, St. Petersburg, Russian Federation; ${ }^{3}$ The First Pavlov State Medical University of St. Petersburg, St. Petersburg, Russian Federation

Background: The level of acute phase indicators does not always correspond to the activity of axial spondyloarthritis ( $\operatorname{axSpA})$. The level of $\mathrm{C}$-reactive protein (CRP) is remain normal in a third of cases of axSpA with present of active clinical symptoms [1]. Search for new biomarker that should have increased sensitivity and specificity compared to the CRP is needed. An alternative biomarker of axSpA activity could be an immunoglobulin (Ig) A antibody to an invariant chain peptide associated with class II human leukocyte antigen (HLA) (anti-CD74) [2]

Objectives: is to determine the level of IgA anti-CD74 in patients with axSpA and its relationship with traditional indicators of disease activity.

Methods: Totally, 137 patients with a reliable diagnosis of axial spondylitis (ASAS criteria, 2009) and 47 healthy volunteers were involved in the study. AxSpA activity indices (ASDAS, BASDAI) were calculated for all patients and IgA levels of anti-CD74, ESR and CRP were determined. The normal level according to the instructions for the laboratory kit for determining the level of $\lg A$ anti-CD74 is $12.0 \mathrm{U} / \mathrm{L}$.

Results: Patients and volunteers characteristics are present in Table 1.

Table 1. Characteristic of the patients with axial spondyloarthritis $(n=137)$ and healthy volunteers $(n=47)$

\begin{tabular}{lcc}
\hline Indicator & \multicolumn{2}{c}{ Results } \\
\hline & AxSpA patients & Healthy volunteers \\
\hline Male, $\mathrm{n}(\%)$ & $101(73.7)$ & $19(40.4)$ \\
Age, years (mean \pm SD) & $43.4 \pm 13.3$ & $49.0 \pm 11.0$ \\
Disease duration, years (mean \pm SD) & $12.6 \pm 8.3$ & \\
Activity indices & & \\
ASDAS, points (mean \pm SD) & $2.29 \pm 1.17$ & \\
BASDAl, points (mean $\pm S D)$ & $3.02 \pm 2.0$ & \\
Laboratory markers & & \\
CRP, mg/L (mean $\pm S D)$ & $9.61 \pm 18.3$ & $9.3 \pm 1.9$ \\
Abnormal level of CRP, $n(\%)$ & $114(83.2)$ & $15(31.9)$ \\
IgA anti-CD74, U/L (mean $\pm S D)($ fig. 1$)$ & $16.9 \pm 11.0$ & $8.5 \pm 7.9$ \\
Abnormal level of IgA anti-CD74, $n(\%)$ & $96(70.1)$ & \\
ESR, mm/h (mean $\pm S D)$ & $24 \pm 7.8$ & \\
\hline
\end{tabular}

A direct relationship was found with a high power between an increase in the level of anti-CD74 $(R=0.667)$ and an increase in the ASDAS $(R=0.857)$ and BASDAI ( $R=0.842)$. The factor analysis showed that an increase in activity level according to ASDAS, BASDAI indices was associated with an increase in concentration of $\lg A$ anti-CD74. While CRP indicators $(R=0.530)$ were associated only with the ASDAS index $(R=0.760)$ (Table 2). 
Table 2. Factor loads of the relationships identified between the concentration of IgA anti-CD74 and the activity indices of axial spondyloarthritis

\begin{tabular}{lccc}
\hline Indicator & \multicolumn{3}{c}{ Factor loading $(\mathrm{R})$} \\
\hline Factor & Factor 1 & Factor 2 & Factor 3 \\
\hline IgA anti-CD74 & - & - & 0.667 \\
BASDAI & - & 0.844 & 0.842 \\
ASDAS & 0.530 & 0.959 & 0.857 \\
BASFI & - & 0.614 & 0.820 \\
CRP & 0.760 & - & - \\
\hline
\end{tabular}

«» no significant association present.
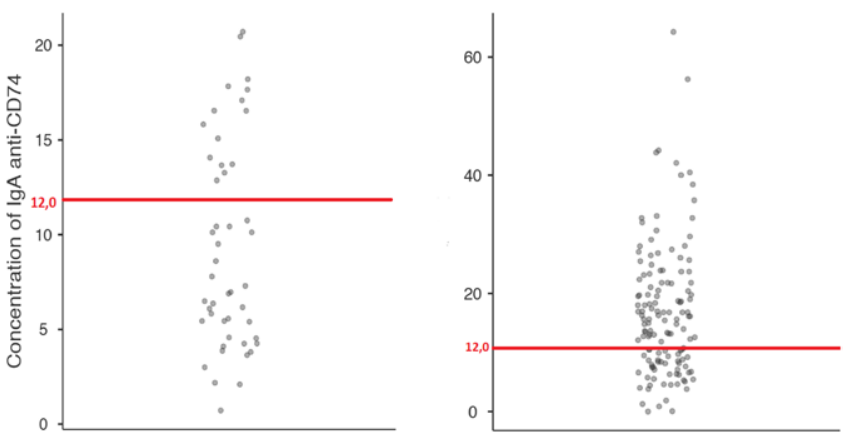

Figure. 1. Concentration of $\lg A$ anti-CD74 for healthy volunteers (left) and patients with axial spondylitis (right)

As compared to controls sensitivity of IgA to anti-CD74 was $64,7 \%$, specificity of this method was $68,1 \%$.

Conclusion: The concentration of IgA to anti-CD74 is increased in $70.1 \%$ of pts with axSpA and associated with an increase in disease activity detected with ASDAS and BASDAI, independently from CRP. More data are needed in detection of sensitivity and specificity of IgA to CD74 in axSpA.

References:

[1] Turina MC, et al. RMD Open. 2017;3(1):e000319. doi: 10.1136/rmdopen-2016000319

[2] Elke Riechers, et al. Arthritis Rheumatol. 2019;71(5):729-735. doi: 10.1002/ art.40777

Disclosure of Interests: Elizaveta Vasilenko: None declared, V Mazurov: None declared, Sergey Lapin: None declared, Irina Kholopova: None declared, Anna Dadalova: None declared, Inna Gaydukova Grant/research support from: JSC BIOCAD, Speakers bureau: Pfizer, Novartis, AbbVie, JSC BIOCAD, Celgene, MSD, Sanofi

DOI: 10.1136/annrheumdis-2020-eular.4364

\section{\begin{tabular}{|l|l}
\hline FRI0598 DMARD-FREE REMISSION IN RHEUMATOID & DMAN
\end{tabular} ARTHRITIS: AN ACHIEVABLE AND SUSTAINABLE OUTCOME? A SYSTEMATIC LITERATURE REVIEW}

M. Verstappen ${ }^{\star 1}$, E. Van Mulligen ${ }^{2}$, P. De Jong ${ }^{2}$, A. Van der Helm - van Mil ${ }^{1,2}$. ${ }^{1}$ Leiden University Medical Center, Rheumatology, Leiden, Netherlands;

${ }^{2}$ Erasmus University Medical Center, Rheumatology, Rotterdam, Netherlands

Background: Current treatment guidelines for rheumatoid arthritis (RA) suggest tapering DMARDs. ${ }^{1}$ Discontinuation of DMARD-treatment is of increasing interest, and DMARD-free remission (DFR) is regarded an important future outcome. ${ }^{23}$ However, lack of knowledge on DFR prevalence, its sustainability, and the characteristics of patients achieving DFR currently hampers the use of DFR as primary outcome.

Objectives: To increase the understanding of DFR in RA, and to support studies aiming to include this as primary outcome, we systematically reviewed the literature to determine prevalence and sustainability of DFR. Potential predictors of DFR were evaluated to increase insight in patient characteristics favourable for achieving this outcome.

Methods: A systematic literature search was performed in March 2019 in multiple databases. All clinical trials and observational studies reporting on discontinuation of DMARDs in RA-patients in remission were included. Our quality assessment included a general assessment and assessment of the description of DFR. Prevalence of DFR and its sustainability, flares during tapering and after DMARD-stop were summarized. Also, potential predictors of achieving DFR were reviewed.
Results: From 631 articles, 51 were included, comprising 14 clinical trials and 5 observational studies. DFR-definition differed, especially for the duration of DMARD-free state. Considering only high and moderate-quality studies, DFR was achieved in 5.0\%-24.3\%, and sustained DFR (duration $>12$ months) in $11.6 \%$ $19.4 \%$. Flares occurred frequently during DMARD-tapering (41.8\%-75.0\%) and in the first year after achieving DFR (10.4\%-11.8\%), whilst late flares, $>1$ year after DMARD-stop, were infrequent (0.3\%-3.5\%). Many patient characteristics lacked association with DFR. Absence of auto-antibodies and shared epitope alleles increased the risk of achieving DFR.

Conclusion: DFR is achievable in RA, and is sustainable in $\sim 10 \%-20 \%$ of patients. ${ }^{1}$ DFR can become an important outcome measure for clinical trials, and requires consistency in the definition. Considering the high rate of flares in the first year after DMARD-stop, a DMARD-free follow-up of $>12$ months is advisable to evaluate sustainability.

References:

[1] Smolen JS, Landewe R, Bijlsma Jea. EULAR recommendations for the management of rheumatoid arthritis with synthetic and biological disease-modifying antirheumatic drugs: 2016 update. Ann Rheum Dis 2017;76(6):960-77. doi: annrheumdis-2016-210715 [pii];10.1136/annrheumdis-2016-210715 [doi]

[2] Ajeganova S, van Steenbergen HW, van Nies JA, et al. Disease-modifying antirheumatic drug-free sustained remission in rheumatoid arthritis: an increasingly achievable outcome with subsidence of disease symptoms. Ann Rheum Dis 2016;75(5):867-73. doi: annrheumdis-2014-207080 [pii];10.1136/ annrheumdis-2014-207080 [doi]

[3] Stamm TA, Machold KP, Aletaha D, et al. Induction of sustained remission in early inflammatory arthritis with the combination of infliximab plus methotrexate: the DINORA trial. Arthritis Res Ther 2018;20(1):174. doi: 10.1186/s13075018-1667-z [doi];10.1186/s13075-018-1667-z [pii]
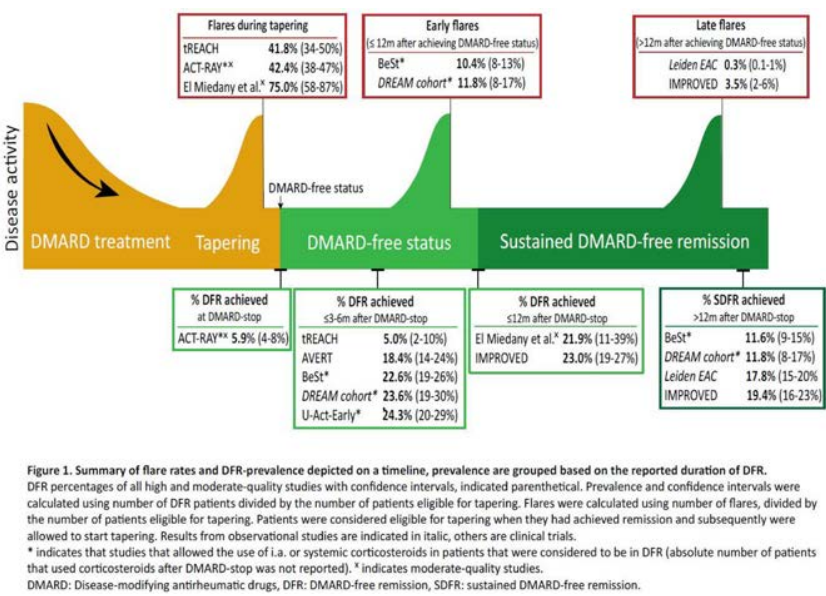

Acknowledgments: We would like to thank J. Schoones, librarian of Leiden University Medical Center, for constructing and carrying out the literature search. Disclosure of Interests: None declared

DOI: 10.1136/annrheumdis-2020-eular.1726

\section{FRI0599 USEFUL II: DERIVATION OF THE LUPUS ARTHRITIS AND MUSCULOSKELETAL DISEASE ACTIVITY SCORE (LAMDA) USING DATA FROM A MULTICENTRE LONGITUDINAL STUDY}

K. Mahmoud ${ }^{1}$, A. Zayat ${ }^{2}$, M. Y. MD Yusof ${ }^{1}$, C. Ciurtin ${ }^{3}$, C. S. Yee ${ }^{4}$, D. Isenberg ${ }^{3}$, L. S. Teh ${ }^{5}$, K. Dutton ${ }^{1}$, D. D'cruz ${ }^{6}$, N. Ng ${ }^{6}$, P. G. Conaghan ${ }^{1}$, P. Emery ${ }^{1}$, C. Edwards ${ }^{7}$, E. Hensor ${ }^{1}$, E. Vital' ${ }^{1}{ }^{1}$ University of Leeds and NIHR Leeds Biomedical Research Centre, Leeds, United Kingdom; ${ }^{2}$ Bradford Teaching Hospitals NHS Foundation Trust, Bradford, United Kingdom; ${ }^{3}$ University College Hospital, London, United Kingdom; ${ }^{4}$ Doncaster and Bassetlaw Teaching Hospitals NHS Foundation Trust, Doncaster, United Kingdom; ${ }^{5}$ Royal Blackburn Teaching Hospital, Blackburn and University of Central Lancashire, Blackburn, United Kingdom; ' ${ }^{6}$ Guy's and St Thomas' NHS Foundation Trust, London, United Kingdom; ${ }^{7}$ University Hospital Southampton NHS Foundation Trust, Southampton, United Kingdom

Background: Musculoskeletal (MSK) disease is the commonest manifestation of SLE. We showed that the MSK components of the BILAG index and SLEDAI have limited sensitivity, specificity and responsiveness compared to ultrasound 